\title{
Statins Protect Against Acute RT-related Rectal Toxicity in Patients with Prostate Cancer: An Observational Prospective Study
}

\author{
ISABELLA PALUMBO ${ }^{1,2}$, FABIO MATRONE $^{1}$, GIAMPAOLO MONTESI ${ }^{1}$, RITA BELLAVITA $^{2}$, \\ MARCO LUPATTELLI ${ }^{2}$, SIMONETTA SALDI $^{1}$, ALESSANDRO FRATTEGIANI ${ }^{2}$, ELEONORA ARENA ${ }^{1}$, \\ CRISTINA MARIUCCI ${ }^{1}$, LORENZO FALCINELLI ${ }^{2}$, VITTORIO BINI ${ }^{3}$ and CYNTHIA ARISTEI ${ }^{1,2}$ \\ ${ }^{1}$ Radiation Oncology Section, University of Perugia, Perugia, Italy; \\ ${ }^{2}$ Radiation Oncology Division, Perugia General Hospital, Perugia, Italy; \\ ${ }^{3}$ Internal Medicine, Endocrine and Metabolic Science Section, University of Perugia, Perugia, Italy
}

\begin{abstract}
Aim: To analyze risk factors for acute rectal toxicity during hypofractionated intensity-modulated radiotherapy (IMRT) for prostate cancer. Patients and Methods: A total of 195 patients received 74.25 Gy in 33 fractions to the prostate and, if involved, to the seminal vescicles $(S V)$. When the risk of $S V$ involvement was $>15 \%$ according to the Roach's formula, they received $62 \mathrm{~Gy}$ in 33 fractions. Overall, 107/195 patients (54.87\%) received hormonal therapy (luteinizing hormone-releasing hormone analogue, anti-androgen, or both). Common Terminology Criteria for Adverse Events version 3.0 was used to classify rectal toxicity. Results: Acute rectal toxicity occurred in 79 $(40.51 \%)$ patients (grade 1 in 44 ). In univariate analysis, use of calcium channel blockers significantly reduced the acute rectal toxicity rate and 3-hydroxy-methylglutaryl CoA reductase inhibitors (statins) significantly reduced the rectal toxicity rate and grade. In multivariate analysis, only statin use was an independent protective factor. Conclusion: In patients with prostate cancer treated with a moderate hypofractionated IMRT schedule, use of statins lowered the incidence and grade of acute rectal toxicity.
\end{abstract}

Radiotherapy (RT) is one therapeutic option for localized prostate cancer (PC) and a dose-response relation has emerged between biochemical disease control and total RT dose (1-4). Clinical and experimental studies demonstrated that prostate adenocarcinoma has a lower $\alpha / \beta$ ratio than

Correspondence to: Isabella Palumbo, Radiation Oncology Section, Department of Surgical and Biomedical Sciences, University of Perugia, 06156 Perugia, Italy. Tel: +39 0755783254, Fax: +39 0755783254, e-mail: isabella.palumbo@unipg.it

Key Words: Prostate cancer, intensity-modulated radiotherapy, hypofractionation, acute rectal toxicity, statins. many other malignancies (average about $1.5 \mathrm{~Gy}$; range $=0.8$ $2.2 \mathrm{~Gy}$ ), suggesting hypofractionation is an optimal treatment strategy for these patients (5). With highly conformal treatment techniques such as intensity-modulated radiotherapy (IMRT), radiation to normal tissue (particularly the rectum) is reduced and its adverse effects are minimized, so that doses can be escalated to the target volume and hypofractionated schedules employed.

The most common acute rectal complications, which occur in up to $25 \%$ of patients, are changes in bowel habits, mild or moderate urgency, diarrhea-like stools, fecal incontinence and bleeding. Since there is mounting evidence that acute damage is linked to late toxicity (6-9), identifying the factors predictive of acute toxicity could improve the patient's quality of life during and after RT and could help clinicians tailor treatment in accordance with the patient's personal characteristics.

In acute rectal toxicity, the role of dosimetric variables is quite well understood and a solid set of dose-volume constraints and logistic curves estimating the associated risk of rectal injury are readily available $(10,11)$. The same consensus does not apply to the impact of clinical variables such as age $(7,12-14)$, and androgen deprivation (15-18), while concomitant medication with 3-hydroxy-methylglutaryl coenzyme-A reductase inhibitors (statins) or antihypertensive drugs seems to have a protective effect $(9,19-21)$.

The present study aimed to investigate the impact of these clinical factors along with dosimetric variables on the risk of developing acute rectal toxicity in patients with localized prostate cancer who received IMRT.

\section{Materials and Methods}

Study population. We prospectively analyzed 195 patients who underwent radical IMRT for localized prostate cancer between May 2009 and August 2014. Inclusion criteria were: histologically proven 
prostate adenocarcinoma, stage cT1-3 and clinically negative lymph nodes. The pre-operative workup included history, focusing on medications for cardiovascular comorbidities, clinical examination, serum prostate-specific antigen (PSA) and a transrectal prostatic ultrasound scan. Pelvic magnetic resonance imaging was performed to define prostatic capsule invasion and seminal vesicle (SV) involvement. In patients with additional risk factors, abdominal computed tomography (CT) and bone scintigraphy were performed to investigate lymph node status and to ruled out bone metastases respectively. Short/long course hormonal therapy with a luteinizing hormone-releasing hormone analog, an anti-androgen or both were prescribed on the basis of adverse prognostic factors (Gleason Score $\geq 7$ and/or basal PSA $\geq 10 \mathrm{ng} / \mathrm{ml}$ and/or T stage $\geq 2 \mathrm{~b}$ ).

Treatments. All patients were treated in the supine position and immobilized by knee and foot support (Combifix ${ }^{\circledR}$, CIVCO Medical Solutions, Orange City, IA, USA). An urethrography was performed in all to identify the prostatic apex. A computed tomographic scan without contrast ( $3 \mathrm{~mm}$ slice thickness and step) was acquired with full bladder (half liter of water was drunk by the patient 45 minutes before the scan). Images were transferred to a treatment planning system (Pinnacle ${ }^{\circledR}$; Philips, Fitchburg, WI, USA); the clinical target volume (CTV) and organs at risks (OARs) were contoured. OARs were the rectum, contoured from the anal canal to the recto-sigmoid junction; the femoral heads; and the bladder. The CTV was the prostate. CTV2 included SV in patients with cT3b stage or risk of SV involvement ( $>15 \%$ according Roach's formula). The whole pelvis was never irradiated. The planning target volumes (PTV1 and eventually PTV2) consisted of the CTVs plus $1 \mathrm{~cm}$ in all directions except at the prostate-rectal interface, where the margin was $0.5 \mathrm{~cm}$. All patients were treated with a 5-field IMRT (one antero-posterior, two anterior oblique, and two posterior oblique) using photons delivered by linear accelerator (Varian Clinac ${ }^{\circledR}$ DHX; Varian Medical Systems, Palo Alto, CA, USA).

A moderate hypofractionated regimen delivered a prescribed dose of $74.25 \mathrm{~Gy}$ in 33 fractions (2.25 Gy/fraction) to the prostate and to the SV when involved. When the SV risked involvement, $62 \mathrm{~Gy}$ in 33 fractions (1.879 Gy/fraction) was administered. OAR dosevolume constraints were: V38<60\%, V57 $<40 \%$, and V66.5 $<25 \%$ (that is the volume receiving $>38,57$ and $66.5 \mathrm{~Gy}$, respectively) for the rectum; V62 $<50 \%$ (that is the volume receiving $>62 \mathrm{~Gy}$ ) for the bladder; and V47.5<10\% (that is the volume receiving $>47.5 \mathrm{~Gy}$ ) for femoral heads.

Acute rectal side-effects, graded according to the Common Terminology Criteria for Adverse Events (CTCAE) version 3.0 (22), were monitored weekly during RT and at 1 and 3 months posttreatment. Late rectal side-effects and disease status were monitored every 4-6 months for the first 5 years, and then annually.

Statistical analyses. The Shapiro-Wilk test assessed the normal distribution of data. Due to their asymmetric distribution, the MannWhitney $U$-test was used to compare continuous variables and the chi-square test with Yates' correction to compare categorical variables. Spearman's rho correlation coefficient analyzed data for correlations. Multivariate logistic regression models were fitted to predict acute toxicity, incorporating all the variables that gave a $p$ value of 0.25 or less in univariate analysis (23). Goodness of fit for the logistic regression models was checked using the Hosmer and Lemeshow test. Odds ratios (ORs) with $95 \%$ confidence intervals (CIs) were also calculated.
Table I. Patient characteristics and dosimetric data.

\begin{tabular}{lc}
\hline Characteristic & Value \\
\hline Age, years* & $74(57-85)$ \\
T-Stage, n (\%) & \\
T1a & $3(1.54)$ \\
T1b & $2(1.03)$ \\
T1c & $28(14.36)$ \\
T2a & $21(10.77)$ \\
T2b & $36(18.46)$ \\
T2c & $83(42.56)$ \\
T3a & $9(4.62)$ \\
T3b & $13(6.67)$ \\
Gleason score, n $(\%)$ & \\
2-6 & $114(58.47)$ \\
7 & $55(28.21)$ \\
8-10 & $26(13.34)$ \\
Basal PSA, ng/ml* & $8.1(1.6-42.59)$ \\
Hormone therapy, n $(\%)$ & $107(54.87)$ \\
Irradiation volume, n $(\%)$ & \\
Prostate & $111(56.9)$ \\
Prostate + SV at risk & $71(36.4)$ \\
Prostate + SV involved & $13(6.7)$ \\
Prostatic volume, cm ${ }^{*}$ & $43.93(16.72-161.60)$ \\
Mean rectal dose, Gy* & $34.39(10.74-48.05)$ \\
Rectal V25, \%* & $69(25-99)$ \\
Rectal V38, \%* & $42(10-65)$ \\
Rectal V57, \%* & $13(3-38)$ \\
Rectal V66.5, \%* & $3(1-10)$ \\
\hline
\end{tabular}

PSA: Prostate-specific antigen; SV: seminal vescicle. *Data are reported as median and range.

Table II. Medication for cardiovascular co-morbidities taken by patients in this study.

\begin{tabular}{lcc}
\hline Medication & Yes, n (\%) & No, n (\%) \\
\hline Anticoagulant drug & $11(5.65)$ & $184(94.35)$ \\
Angiotensin-converting enzyme inhibitor & $73(37.44)$ & $122(62.56)$ \\
Angiotensin II receptor antagonist & $37(18.98)$ & $158(81.02)$ \\
Beta blocker & $35(17.95)$ & $160(82.05)$ \\
Calcium channel blocker & $42(21.54)$ & $153(78.46)$ \\
Diuretic & $54(27.69)$ & $141(72.31)$ \\
Statin & $55(28.21)$ & $140(71.79)$ \\
\hline
\end{tabular}

All calculations were carried out with IBM-SPSS ${ }^{\circledR}$ version 22.0 (IBM Corp., Armonk, NY, USA). A two-sided $p$-value less than 0.05 was considered significant.

\section{Results}

The patient's characteristics and dosimetric data are given in Table I. Most patients had T2c stage disease (83/195; $42.56 \%$ ). Most Gleason scores were 2-6 (114/195; 58.47\%). 
Table III. Univariate analysis of potential predictors for acute rectal toxicity.

\begin{tabular}{lcc}
\hline & \multicolumn{2}{c}{ Rectal toxicity } \\
\cline { 2 - 3 } & Yes (79 patients) & No (116 patients) \\
\hline Age, years* & $74(57-85)$ & $74(58-83)$ \\
Prostatic volume, cm3* & $43.93(22.57-146.51)$ & $43.88(16.72-161.14)$ \\
Mean rectal dose, Gy* & $33.52(11.83-48.05)$ & $34.77(10.73-46.77)$ \\
Rectal V25, \%* & $67(25-97)$ & $70(35-99)$ \\
Rectal V38, \%* & $42(10-65)$ & 0.965 \\
Rectal V57, \%* & $14(4-38)$ & 0.523 \\
Rectal V66.5, \%* & $3(1-10)$ & $0.433(3-28)$ \\
Irradiation volume: Prostate/prostate+SV at risk/prostate+SV involved & $50 / 23 / 6$ & $3(1-10)$ \\
Hormonal therapy: Yes/no & $44 / 35$ & $61 / 48 / 7$ \\
Anticoagulant: Yes/no & $3 / 76$ & $63 / 53$ \\
Angiotensin-converting enzyme inhibitor: Yes/no & $26 / 53$ & $8 / 108$ \\
Angiotensin II receptor antagonist: Yes/no & $19 / 60$ & 0.100 \\
Beta blocker: Yes/no & $13 / 66$ & 0.217 \\
Calcium channel blocker: Yes/no & $11 / 68$ & 0.964 \\
Diuretic: Yes/no & $20 / 59$ & 0.545 \\
Statin: Yes/no & $15 / 64$ & 0.354 \\
\hline
\end{tabular}

SV: Seminal vescicle. *Data are reported as median and range.

Hormonal therapy was prescribed to $107 / 195$ (54.87\%) cases. RT was administered only to the prostatic gland in $111 / 195(56.9 \%)$ patients.

The median follow-up time was 26 (range=3-60) months. A total of 79 patients $(40.51 \%)$ developed acute rectal toxicity which was grade 1 in $44(55.70 \%)$, grade 2 in 33 $(41.77 \%)$ and grade 3 in $2(2.53 \%)$. No grade 4 toxicities were observed.

Medications for cardiovascular comorbidities are described in Table II. The majority of patients (137/195; $70.26 \%$ ) were taking anti-hypertensive drugs, most in combination therapies; 42 patients $(27.69 \%)$ were taking calcium channel blocker and 55 patients $(28.21 \%)$ statins.

In univariate analysis, potential predictors for acute rectal toxicity analyzed were: age, prostatic volume, irradiation volumes, rectal dosimetric parameters (mean rectal dose, V25, V38, V66.5, V57), use of anticoagulants, angiotensinconverting enzyme inhibitors, angiotensin II receptor antagonists, beta blockers, calcium channel blockers, diuretics and statins. In multivariate analysis, age, rectal V66.5, irradiation volume, and use of calcium channel blockers, angiotensin II receptor antagonists and statins were analyzed.

Univariate analysis showed that statin and calcium channel blocker administration significantly reduced the rate of acute rectal toxicity (Table III), while multivariate analysis confirmed that only statins were an independent protective factor. Increasing age emerged as an independent risk factor (Table IV). Statin administration significantly
Table IV. Multivariate analysis of potential predictors for acute rectal toxicity.

\begin{tabular}{lccc}
\hline Variable & $\begin{array}{c}\text { Odds } \\
\text { ratio }\end{array}$ & $\begin{array}{c}95 \% \text { Confidence } \\
\text { interval }\end{array}$ & \\
\hline Age & 1.075 & $1.000-1.155$ & 0.049 \\
Rectal V66.5 & 1.109 & $0.972-1.266$ & 0.123 \\
Irradiation volume & 0.989 & $0.581-1.680$ & 0.967 \\
Calcium channel blocker & 0.430 & $0.178-1.035$ & 0.060 \\
Angiotensin II receptor antagonist & 1.489 & $0.627-3.532$ & 0.367 \\
Statin & 0.456 & $0.211-0.982$ & 0.045 \\
\hline
\end{tabular}

$(p=0.029)$ reduced the acute rectal toxicity grade: grade $0:$ 40/116 patients on statins $(34.48 \%)$; grade 1: $12 / 44$ patients on statins $(27.27 \%)$; grade 2: $3 / 33$ patients on statins $(9.09 \%)$; grade 3: $0 / 2$ patients on statins.

\section{Discussion}

In the present study, a moderate hypofractionated IMRT schedule with a 2.25 Gy single dose, was administered. A low acute rectal toxicity rate, prevalently grade 1 , was observed. Other than the fractionation schedule $(24,25)$, the toxicity potential depends on many variables, such as dosimetric parameters $(10,11)$ and concomitant treatments such as hormone therapy (15-17) and medications for other conditions $(9,19-21)$. 
In our patient series, no significant correlation emerged between acute rectal toxicity and dosimetric variables, which may have depended on our adherence to dose constraints that were adjusted for our hypofractionation schedule (V38 $<60 \%$, V57 $<40 \%$ and V66.5 <25\%). Generally speaking, grade 2 or more rectal toxicity is related to maximum doses $\geq 60$ Gy (11). More specifically, it is significantly reduced when $15 \%$ of the rectum receives under 70 Gy (V70 <15\%) or when $10 \%$ receives under 75 Gy (V75 <10\%) (26-27). Consequently, some authors proposed a set of constraints, in conventional fractionation, which were associated with a significant reduction in acute rectal toxicity: V $60 \leq 40 \%$, $\mathrm{V} 40 \leq 65 \%, \mathrm{~V} 70 \leq 15 \%$ (28).

In the present univariate analysis, both use of calcium channel blockers and of statins were associated a lower incidence of acute rectal toxicity, but in multivariate analysis only statins maintained their protective effect.

RT-related toxicity might be reduced by some specific classes of drugs, such as statins and calcium channel blockers $(9,19-21)$. The statin-related drop in rectal cancer toxicity might be due to their anti-fibrotic, anti-inflammatory and anti-thrombotic effects, which were demonstrated in vitro and in vivo (19). On the other hand, the protective effect of calcium channel blockers could be linked to an imbalance in calcium homeostasis which is produced by radiation injury, to their antioxidant properties and to their counteracting RT-induced endothelial damage (20).

No significant correlations were observed in our study between neoadjuvant/concomitant hormonal therapy and acute rectal toxicity. Although the role of hormonal therapy in rectal toxicity remains controversial $(15,17,18)$, the time interval between starting hormonal therapy and RT was postulated to play a major role. Zelefsky et al. showed that neoadjuvant hormonal therapy reduced prostate volume, thus reducing the target volume significantly and enhancing sparing of OARs (29). On the other hand, although occurring mainly in the first 3 months, hormone-induced shrinkage of prostate volume was hypothesized to take up to 12 months after starting hormonal therapy. As the prostate shrinks, OARs move and a larger proportion of healthy rectal wall volume risks being included in a too high isodose, leading to rectal toxicity (15).

Rather controversially, acute rectal toxicity correlated significantly with advanced age in our cohort. On the contrary, Jereczek-Fossa et al. showed a significant increase in acute rectal toxicity was linked to age $\leq 65$ years in 973 patients who underwent RT for prostate cancer (7). Other reports suggested age had a marginal predictive role and was not associated with an increased incidence and grade of acute rectal toxicity (1214). Explanations that may account for all these diverse findings is that the biological age, co-morbidities and the effect of lifestyles vary greatly from one individual to another. Furthermore, different patient selection criteria and data analysis systems may have been used in the various studies.

\section{Conclusion}

In the present prospective observational study, a homogeneously treated cohort of patients with prostate cancer received a moderate hypofractionated IMRT schedule. The close adherence to dose constraints and statin administration were associated with a low incidence of acute rectal toxicity. Future prospective studies on larger cohorts of patients with prostate cancer are needed to define the role of statins as protective agents against acute rectal toxicity and so improve stratification of patients at risk of chronic sequelae since a correlation has emerged between acute and late toxicity rates (6-9).

\section{Conflicts of Interest}

The Authors declare that they have no conflict of interest in regard to this study.

\section{References}

1 Dearnaley DP, Jovic G, Syndikus I, Khoo V, Cowan RA, Graham JD Aird EG, Bottomley D, Huddart RA, Jose CC, Matthews JH, Millar JL, Murphy C, Russell JM, Scrase CD, Parmar MK and Sydes MR: Escalated-dose versus control-dose conformal radiotherapy for prostate cancer: long-term results from the MRC RT01 randomised controlled trial. Lancet Oncol 15(4): 464-473, 2014.

2 Pollack A, Zagars GK, Starkschall G, Antolak JA, Lee JJ, Huang E, von Eschenbach AC, Kuban DA and Rosen I: Prostate cancer radiation dose response: results of the M. D. Anderson phase III randomized trial. Int J Radiat Oncol Biol Phys 53(5): 1097-1105, 2002.

3 Eade TN, Hanlon AL, Horwitz EM, Buyyounouski MK, Hanks GE and Pollack A: What dose of external-beam radiation is high enough for prostate cancer? IntJ Radiat Oncol Biol Phys 68(3): 682-689, 2007.

4 Zietman AL, Bae K, Slater JD, Shipley WU, Efstathiou JA, Coen JJ, Bush DA, Lunt M, Spiegel DY, Skowronski R, Jabola BR and Rossi CJ: Randomized trial comparing conventional-dose with high-dose conformal radiation therapy in early-stage adenocarcinoma of the prostate: long-term results from Proton Radiation Oncology Group/American College of Radiology 95-09. J Clin Oncol 28(7): 1106-1111, 2010.

5 Hegemann NS, Guckenberger M, Belka C, Ganswindt U, Manapov $\mathrm{F}$ and Li M: Hypofractionated radiotherapy for prostate cancer. Radiat Oncol 9: 275, 2014.

6 Dorr W and Hendry JH: Consequential late effects in normal tissues. Radiother Oncol 61(3): 223-231, 2001.

7 Jereczek-Fossa BA, Zerini D, Fodor C, Santoro L, Serafini F, Cambria R, Vavassori A, Cattani F, Garibaldi C, Gherardi F, Ferrari A, Rocco B, Scardino E, de Cobelli O and Orecchia R: Correlation between acute and late toxicity in 973 prostate cancer patients treated with three-dimensional conformal external beam radiotherapy. Int J Radiat Oncol Biol Phys 78(1): 26-34, 2010. 
8 Lock M, Best L, Wong E, Bauman G, D’Souza D, Venkatesan V, Sexton T, Ahmad B, Izawa J and Rodrigues G: A phase II trial of arc-based hypofractionated intensity-modulated radiotherapy in localized prostate cancer. Int J Radiat Oncol Biol Phys 80: 1306-1315, 2011.

9 Cella L, D'Avino V, Liuzzi R, Conson M, Doria F, Faiella A, Loffredo F, Salvatore M and Pacelli R: Multivariate normal tissue complication probability modeling of gastrointestinal toxicity after external beam radiotherapy for localized prostate cancer. Radiat Oncol 8: 221, 2013.

10 Fiorino C, Valdagni R, Rancati $\mathrm{T}$ and Sanguineti $\mathrm{G}$ : Dose-volume effects for normal tissues in external radiotherapy: pelvis. Radiother Oncol 93(2): 153-167, 2009.

11 Michalski JM, Gay H, Jackson A, Tucker SL and Deasy JO: Radiation dose-volume effects in radiation-induced rectal injury. Int J Radiat Oncol Biol Phys 76(3Suppl): S123-S129, 2010.

12 Payne HA, Hughes S: Radical radiotherapy for high-risk prostate cancer in older men. Oncologist 17: 9-15, 2012.

13 Jani AB, Parikh SD, Vijayakumar S and Gratzle J: Analysis of influence of age on acute and chronic radiotherapy toxicity in treatment of prostate cancer. Urology 65(6): 1157-1162, 2005.

14 Bellavita R, Scricciolo M, Bini V, Arcidiacono F, Montesi G, Lancellotta V, Zucchetti C, Lupattelli M, Palumbo I and Aristei $\mathrm{C}$ : Radiotherapy for early-stage prostate cancer in men under 70 years of age. Tumori 102(2): 209-216, 2016.

15 Sanguineti G, Marcenaro M, Franzone P, Foppiano F and Vitale $\mathrm{V}$ : Neoadjuvant androgen deprivation and prostate gland shrinkage during conformal radiotherapy. Radiother Oncol 66: 151-157, 2003.

16 Liu M, Pickles T, Agranovich A, Berthelet E, Duncan G, Keyes M, Kwan W,McKenzie M, Morris J, Pai H, Tyldesley S and Wu $\mathrm{J}$ : Impact of neoadjuvant androgen ablation and other factors on late toxicity after external beam prostate radiotherapy. Int J Radiat Oncol Biol Phys 58(1): 59-67, 2004.

17 Valdagni R, Rancati T, Fiorino C, Fellin G, Magli A, Baccolini M, Bianchi C,Cagna E, Greco C, Mauro FA, Monti AF, Munoz F, Stasi M, Franzone P and Vavassori V: Development of a set of nomograms to predict acute lower gastrointestinal toxicity for prostate cancer 3D-CRT. Int J Radiat Oncol Biol Phys 71(4): 1065-1073, 2008.

18 Denham JW, Wilcox C, Lamb DS, Spry NA, Duchesne G, Atkinson C, Matthews J,Turner S, Kenny L, Tai KH, Gogna NK, Ebert M, Delahunt B, McElduff P and Joseph D: Rectal and urinary dysfunction in the TROG 03.04 RADAR trial for locally advanced prostate cancer. Radiother Oncol 105(2): 184-192, 2012.

19 Wedlake LJ, Silia F, Benton B, Lalji A, Thomas K, Dearnaley DP, Blake P, Tait D, Khoo VS and Andreyev HJ: Evaluating the efficacy of statins and ACE-inhibitors in reducing gastrointestinal toxicity in patients receiving radiotherapy for pelvic malignancies. Eur J Cancer 48(14): 2117-2124, 2012.
20 Massaccesi M, Ippolito E, Deodato F, Cilla S, Digesù C, Macchia G, Caravatta L, Picardi V, Mattiucci GC, Di Lallo A, Cuscunà D, Cellini N, Valentini V and Morganti AG: Radioprotective effect of calcium channel blockers against late rectal bleeding in prostate cancer. Radiol Med 119(5): 343-347, 2014.

21 Liu X, Li J, Wu T, Schild SE, Schild MH, Wong W, Vora S and Fatyga M: Patient-specific characteristics are an important factor that determines the risk of acute grade $\geq 2$ rectal toxicity in patients treated for prostate cancer with IMRT and daily image guidance based on implanted gold markers. OMICS J Radiol 5(3): pii: $225,2016$.

22 Common Terminology Criteria for Adverse Events (CTCAE) version 3.0 Web site https://ctep.cancer.gov/ protocol development/electronic_applications/docs/ctcaev3.pdf.Accessed December 4, 2016.

23 Hosmer DW and Lemeshow S: Applied Logistic Regression. John Wiley \& Sons Inc: New York, USA, 2000.

24 Lukka H, Hayter C, Julian JA, Warde P, Morris WJ, Gospodarowicz M, Levine M, Sathya J, Choo R, Prichard H, Brundage $\mathrm{M}$ and Kwan W: Randomized trial comparing two fractionation schedules for patient with localized prostate cancer. Int J Clin Oncol 23(25): 6132-6138, 2005.

25 Pollack A, Hanlon AL, Horwitz EM, Feigenberg SJ, Konski AA, Movsas B, Greenberg RE, Uzzo RG, Ma CM, McNeeley SW, Buyyounouski MK and Price RA Jr: Dosimetry and preliminary acute toxicity in the first 100 men treated for prostate cancer on a randomized hypofractionation dose escalation trial. Int J Radiat Oncol Biol Phys 64: 518-526, 2006.

26 Michalski JM, Gay H, Jackson A, Tucker SL and Deasy JO: Radiation dose-volume effects in radiation-induced rectal injury. Int J Radiat Oncol Biol Phys 76: S123-S129, 2010.

27 Michalski JM, Yan Y, Watkins-Bruner D, Bosch WR, Winter K, Galvin JM, BaharyJP, Morton GC, Parliament MB and Sandler HM: Preliminary toxicity analysis of 3-dimensional conformal radiation therapy versus intensity-modulated radiation therapy on the high-dose arm of the Radiation Therapy Oncology Group 0126 prostate cancer trial. Int J Radiat Oncol Biol Phys 87(5): 932-938, 2013.

28 Gulliford SL, Foo K, Morgan RC, Aird EG, Bidmead AM, Critchley H, Evans PM, Gianolini S, Mayles WP, Moore AR, Sánchez-Nieto B, Partridge M, Sydes MR, Webb S and Dearnaley DP: Dose-volume constraints to reduce rectal side-effects from prostate radiotherapy: evidence from MRC RT01 Trial ISRCTN 47772397. Int J Radiat Oncol Biol Phys 76(3): 747-754, 2010.

29 Zelefsky MJ and Harrison A: Neoadjuvant androgen ablation prior to radiotherapy for prostate cancer: reducing the potential morbidity of therapy. Urology 49: 38-45, 1997.

Received December 20, 2016

Revised January 28, 2017

Accepted February 1, 2017 